NBER WORKING PAPER SERIES

\title{
TRADE LINKAGES AND OUTPUT-MULTIPLIER EFFECTS: A STRUCTURAL VAR APPROACH WITH A FOCUS ON ASIA
}

\author{
Tilak Abeysinghe \\ Kristin Forbes \\ Working Paper 8600 \\ http://www.nber.org/papers/w8600 \\ NATIONAL BUREAU OF ECONOMIC RESEARCH \\ 1050 Massachusetts Avenue \\ Cambridge, MA 02138 \\ November 2001
}

An earlier draft of this paper was titled "Measuring the Contagious Effect of the Asian Crisis on Total Production: A Structural VAR Approach". Thanks to Adrian Pagan, Michael McAleer, Basant Kapur, Tan Lin Yeok, Wayne Simpson and Norman Cameron for valuable comments and suggestions. Further thanks to Rajaguru Gulasekaran for excellent research assistance. This research was partially supported by National University of Singapore research grant RP3972032. The views expressed herein are those of the authors and not necessarily those of the National Bureau of Economic Research.

(C) 2001 by Tilak Abeysinghe and Kristin Forbes. All rights reserved. Short sections of text, not to exceed two paragraphs, may be quoted without explicit permission provided that full credit, including $(\mathrm{C}$ notice, is given to the source. 
Trade Linkages and Output-Multiplier Effects:

A Structural VAR Approach with a Focus on Asia

Tilak Abeysinghe and Kristin Forbes

NBER Working Paper No. 8600

November 2001

JEL No. C32, C50

\begin{abstract}
This paper develops a structural VAR model to measure how a shock to one country can affect the GDP of other countries. It uses trade linkages to estimate the multiplier effects of a shock as it is transmitted through other countries' output fluctuations. The paper introduces a new specification strategy that significantly reduces the number of unknowns and allows cross-country relationships to vary over time. Then it uses this model to examine the impact of shocks to 11 Asian countries, the U.S. and the rest of the OECD. The model produces reasonably good short-term forecasts. Impulse-response matrices suggest that these multiplier effects are large and significant and can transmit shocks in very different patterns than predicted from a bilateral-trade matrix. For example, due to these output-multiplier effects, a shock to one country can have a large impact on countries that are relatively minor bilateral trading partners.
\end{abstract}

Tilak Abeysinghe

Department of Economics

National University of Singapore

10 Kent Ridge Crescent

Singapore 119260

Email: tilakabey@nus.edu.sg

Fax: (65) 775-2646

URL: http://courses.nus.edu.sg/course/ecstabey/Tilak.html

Kristin J. Forbes

Sloan School of Management, E52-446

Massachusetts Institute of Technology

50 Memorial Drive

Cambridge, MA 02142

and NBER

Email: kjforbes@mit.edu

Fax: (617) 258-6855

URL: http://web.mit.edu/kjforbes/www 


\section{INTRODUCTION}

Why did the July 1997 devaluation of the Thai baht spur major currency realignments in Indonesia, Malaysia, the Philippines and Singapore within a few weeks? Why did the December 1997 devaluation of the Korean won affect currencies and stock markets around the world-even in many countries with few direct trade or investment links to Korea? In the past few years, an extensive literature has attempted to answer these sorts of questions. ${ }^{1}$ This research has spawned the widespread use of terms and phrases such as contagion, interdependence, spillovers, and the Asian Flu. Despite the attention paid to these topics, there continues to be little agreement on why a crisis in a relatively small economy can have such widespread global effects, or even how to define terms such as contagion and spillovers.

This paper avoids the debate on definitions and instead focuses on measuring two specific linkages that could transmit a crisis or shock from one country to another. The first linkage is bilateral-trade flows. How important are export shares in determining a country's vulnerability to a crisis that originates in a trading partner? Direct trade linkages are fairly straightforward to document and have been examined in other papers. Most of these papers argue that bilateral-trade flows are important determinants of a country's vulnerability to a crisis, but that direct trade flows can only explain a small portion of the global effects of most recent crises. $^{2}$ This paper's estimates support this conclusion.

The main contribution of this paper is the modelling and estimation of a second linkage: how a shock to one country can also have multiplier effects through its impact on output and growth in other economies. It is extremely difficult to measure the magnitude of these indirect multiplier effects, since measurement involves estimating a matrix connecting the output of all

\footnotetext{
${ }^{1}$ For an excellent overview of this literature, see Claessens, Dornbusch and Park (2001). Also see Goldstein (1998), Norland et al. (1999), Chapter III in International Monetary Fund (1999), and the collection of papers in Claessens and Forbes (2001).

${ }^{2}$ For a survey of this literature and empirical evidence at the industry level, see Forbes (2001). For empirical results at the country and firm level, see Glick and Rose (1999) and Forbes (2000), respectively.
} 
countries in the world. This paper's estimates suggest that these indirect multiplier effects can be important and can transmit crises through very different patterns than predicted by direct, bilateral-trade flows. A series of impulse response functions shows that due to these indirect multiplier effects, a shock to one country can have a large impact on other countries that are relatively minor trading partners.

In order to estimate these output-multiplier linkages, a substantial portion of this paper develops a structural VAR based on realistic identification assumptions. This model avoids adopting an arbitrary recursive system as is frequently done in the VAR literature. More specifically, the paper uses bilateral-trade flows to estimate a model linking output growth across countries. Several previous papers have used VARs to link a variety of macroeconomic variables across nations, but most of these models are problematic due to: profligate parameterisation, arbitrary identification restrictions, and poor forecasting performance. Another key contribution of this model is that cross-country relationships are allowed to vary over time. This is critical when estimating relationships over long periods of time or after a crisis. This methodology not only provides relatively good forecasts, but also may be useful in a wide variety of other applications with a shortage of realistic, theory-based identification restrictions.

Although the structural VAR developed in this paper has a number of advantages, it is also important to note its limitations. The paper uses trade flows between countries to proxy for a wide variety of cross-country linkages: flows of goods and services, flows of foreign direct investment, flows of bank lending, flows of mutual fund investment, flows of migrants and workers, trade competition in third markets, etc. The paper does not try to measure and isolate the impact of each of these cross-country linkages. It focuses on trade flows because these statistics are more widely available and consistently measured across countries, as well as highly correlated with other cross-country linkages. Although a greater level of disaggregation in crosscountry linkages would be useful, it is extremely difficult to obtain the requisite data at a high 
enough frequency and to formulate realistic identification assumptions to estimate the resulting model. ${ }^{3}$ Moreover, the structural VAR developed in this paper is explicitly designed to adjust for time-varying omitted variables that are not incorporated in bilateral-trade flows.

After developing this structural VAR model, the paper uses this framework to estimate trade linkages and output-multiplier effects between most of Asia and its major trading partners. More specifically, it estimates direct and indirect linkages between the ASEAN-4 (Indonesia, Malaysia, the Philippines, and Thailand), the NIE-4 (Hong Kong, Singapore, South Korea, and Taiwan), China, Japan, the U.S., and the rest of the OECD (called ROECD). Estimates of indirect linkages between countries (as measured by the multiplier effects from changes in output growth in other countries) often yield very different predictions about countries' vulnerability to crises than predicted by focusing only on bilateral-trade linkages. A series of impulse response functions show that even if bilateral-trade linkages between two countries are weak, a shock to one of the countries can have a significant effect on the other through the indirect impact on other countries' output.

The remainder of the paper is as follows. Section 2 develops the structural VAR model and discusses the advantages and disadvantages of this approach. Section 3 compiles the necessary data and discusses shortcomings with these statistics. Section 4 estimates the model using several different procedures and Section 5 examines the model's forecasting ability. Section 6 presents the central empirical results: a series of impulse response functions documenting the importance of direct trade linkages and indirect multiplier effects in predicting the global impact of a shock to a specific country. The final section of the paper concludes.

\footnotetext{
${ }^{3}$ Project LINK (Ball, 1973) and the MSG2 model (developed in McKibbin and Sachs, 1991) aggregate individual country models in an attempt to more accurately estimate these various global linkages. The former was unsuccessful, with low predictive power and high standard errors, primarily because of inconsistent data and models across countries. Since the latter is a computable general-equilibrium model (CGE), it is not suitable for forecasting.
} 


\section{METHODOLOGY}

This section develops the structural VAR model that is used to calculate the estimates in the remainder of the paper. In order to capture both direct trade linkages as well as indirect multiplier effects through output fluctuations in other nations, we develop a model simultaneously equating output supply and demand across all countries in the world. We begin by focusing on the determinants of total output $\left(Y_{i}\right)$ for an individual country $i$. The later part of this section extends the framework to a system of equations linking all $n$ countries in the world (with $i=1,2, \ldots, n$ ). Since we initially focus on only one country, we drop the subscript $i$ to simplify notation.

A country's output can be written as:

$$
Y=X+A
$$

where $X$ and $A$ are the export and non-export components of output, respectively. The country's total exports are the sum of exports to each of the other (n-1) countries and (1) can be expressed as:

$$
Y=\sum_{j=1}^{n} X_{j}+A
$$

where $i \neq j$. This inequality condition continues to apply to all of the equations below.

Writing equation (2) in terms of growth rates instead of levels yields:

$$
\frac{d Y}{Y}=\frac{1}{Y}\left[\sum_{j=1}^{n} d X_{j}+d A\right]
$$

Next, we specify exports from country $i$ to country $j$ as a reduced-form function of output in country $j:^{4}$

$$
X_{j}=X_{j}\left(Y_{j}\right)
$$

Differentiating (4) yields: 


$$
d X_{j}=\frac{\partial X_{j}}{\partial Y_{j}} d Y_{j}
$$

Next, insert (5) into (3):

$$
\frac{d Y}{Y}=\frac{1}{Y} \sum_{j=1}^{n}\left(\frac{\partial X_{j}}{\partial Y_{j}} d Y_{j}\right)+\frac{d A}{Y}
$$

which can be rearranged as

$$
\frac{d Y}{Y}=\frac{X}{Y} \sum_{j=1}^{n}\left(\eta_{j} \frac{X}{X} \frac{d Y_{j}}{Y_{j}}\right)+\frac{d A}{Y}
$$

where $\eta_{j}=\left(\partial X_{j} / \partial Y_{j}\right)\left(Y_{j} / X_{j}\right)$ is the income elasticity of exports with respect to country $j$ 's income.

Next, to simplify this equation we make an assumption underlying most aggregate export-demand equations, that the income elasticities are equal across countries. As a result, $\eta_{j}=$ $\eta$ and after adding country and time subscripts and using lower-case letters to indicate growth rates, equation (7) can be written as:

$$
y_{i t}=\alpha_{i} y_{i t}^{f}+u_{i t}
$$

where:

$$
\begin{aligned}
& \alpha=\eta X / Y \\
& y^{f}=\sum\left(X_{j} / X\right) y_{j}
\end{aligned}
$$

and $u_{i t}$ captures any omitted variables not included in trade linkages. A useful characteristic of equation (8) is that the right-hand side variable is an export-share weighted average of output growth rates. Equally important is the characteristic that each export share is allowed to vary

\footnotetext{
${ }^{4}$ The model can be extended in a straightforward manner to include a vector of other variables in the export function. Abeysinghe (2001a, 2001b) provides this extension. We do not include these additional variables in this version of the model since they are not included in the estimation in Section 4.
} 
over time. $^{5} \mathrm{~A}$ final point is that $\alpha_{i}=\eta X / Y$ is assumed to be time invariant. This assumption is examined in detail in Section 4 (and is shown to be realistic).

Equation (8) is central to the estimation results reported below and highlights the differences between this paper and previous work, as well as the key assumptions implicit in this framework. If output growth in every country $j$ is exogenous to output growth in country $i$ (with $i \neq j$ ) then equation (8) would capture the direct impact of a shock in country $j$ on country $i$. In other words, if there was a negative shock to Japanese growth, equation (8) would measure how direct trade linkages transmit this shock to a country such as Thailand by reducing exports from Thailand to Japan. This is the measure used in most other papers examining the importance of bilateral-trade linkages in the international transmission of shocks, but it ignores any indirect effects of the initial shock on the output of other countries.

The goal of this model and paper, however, is to also estimate the indirect multiplier effect of the shock through output growth in other countries. To do so, it assumes that output growth in every country $j$ is not exogenous to output growth in every other country $i$. Instead equation (8) considers not only how slower growth in Japan directly affects exports (and therefore growth) in Thailand, but also how slower growth in Japan reduces exports from Korea and Indonesia, which in turn reduces growth in these countries and their demand for exports from Thailand.

Next, as defined above in equation (8), $u_{i t}$ captures any omitted variables not included in trade linkages. These omitted variables are likely to be correlated over time as well as across equations. Instead of trying to model these linkages explicitly, we assume that the vector $u_{t}=$ $\left(u_{1 t}, u_{2 t}, \ldots u_{n t}\right)^{\prime}$ follows a vector ARMA process, $D(L) u_{t}=E(L) e_{t}$, where $D(L)$ and $E(L)$ are vector polynomials in the lag operator $L$ of orders $p^{*}$ and $q^{*}$, respectively, and $e_{t}$ is a vector white noise

\footnotetext{
${ }^{5}$ Export shares could vary over time due to a number of factors such as: changes in tariffs or other trade restrictions; changes in transportation costs; exchange-rate movements; or even unusual weather patterns
} 
process with a zero mean and a diagonal covariance matrix. Using this error structure and rewriting (8) in vector format yields:

$$
\begin{aligned}
& y_{t}=A y_{t}^{f}+u_{t} \\
&=A y_{t}^{f}+D(L)^{-1} E(L) e_{t} \\
&=A y_{t}^{f}+\frac{D(L)^{*}}{|D(L)|} E(L) e_{t}, \text { or } \\
&|D(L)| y_{t}=|D(L)| A y_{t}^{f}+v_{t}
\end{aligned}
$$

where $A=\operatorname{diag}\left(\alpha_{1}, \alpha_{2}, \ldots, \alpha_{n}\right),|D(L)|$ and $D(L)^{*}$ are the determinant and adjoint matrices of $D(L)$, respectively, and $v_{t}=D(L)^{*} E(L) e_{t}$ is an $(\mathrm{n} \times 1)$ vector. Note that every equation of $(9 \mathrm{~b})$ has the same AR polynomial given by $|D(L)|$, while each $v_{i t}$ follows a separate MA process. ${ }^{6}$

Next, instead of attempting to model $v_{i t}$ as an MA process, we assume that the serial correlation of $v_{i t}$ can be captured by a sufficiently rich AR structure. This has the additional benefit of relaxing the constraint that each equation of (9b) must follow the same AR polynomial. Equation (8) can therefore be expressed as an autoregressive distributed lag model with white noise errors:

$$
y_{i t}=\lambda_{i}+\sum_{j=1}^{p} \phi_{j i} y_{i t-j}+\sum_{j=0}^{p} \beta_{j i} y_{i t-j}^{f}+\varepsilon_{i t}
$$

where $y_{i t}^{f}=\sum_{j=1}^{n} w_{i j} y_{j t}, i \neq j$ and $w_{i j}$ is the export share from the $i$ th country to country $j$. The export shares must sum to unity.

The entire system of equations is formed by estimating equation (10) for each of the $n$ countries in the world. Although these $n$ equations appear to take the form of seemingly unrelated regressions (SUR), they can also be expressed as a structural VAR. This structural

which affect commodity production. We assume that any changes in export shares are independent of the elasticities of foreign demand.

${ }^{6}$ These results follow from Zellner and Palm (1974). 
VAR formulation is useful for the purpose of estimation, forecasting, and impulse response analysis. More specifically, if $n=3$ and $p=1$, then the system of equations can be written:

$$
\begin{gathered}
\left(\begin{array}{ccc}
1 & -\beta_{01} w_{12} & -\beta_{01} w_{13} \\
-\beta_{02} w_{21} & 1 & -\beta_{02} w_{23} \\
-\beta_{03} w_{31} & -\beta_{03} w_{32} & 1
\end{array}\right)\left(\begin{array}{l}
y_{1 t} \\
y_{2 t} \\
y_{3 t}
\end{array}\right)=\left(\begin{array}{l}
\lambda_{1} \\
\lambda_{2} \\
\lambda_{3}
\end{array}\right)+ \\
\left(\begin{array}{ccc}
\phi_{11} & \beta_{11} w_{12} & \beta_{11} w_{13} \\
\beta_{12} w_{21} & \phi_{22} & \beta_{12} w_{23} \\
\beta_{13} w_{31} & \beta_{13} w_{32} & \phi_{33}
\end{array}\right)\left(\begin{array}{l}
y_{1 t-1} \\
y_{2 t-1} \\
y_{3 t-1}
\end{array}\right)+\left(\begin{array}{l}
\varepsilon_{1 t} \\
\varepsilon_{2 t} \\
\varepsilon_{3 t}
\end{array}\right)
\end{gathered}
$$

This can be expressed more compactly as:

$$
\left(B_{0} * W\right) y_{t}=\lambda+\left(B_{1} * W\right) y_{t-1}+\varepsilon_{t}
$$

where

$$
\mathrm{B}_{0}=\left(\begin{array}{ccc}
1 & -\beta_{01} & -\beta_{01} \\
-\beta_{02} & 1 & -\beta_{02} \\
-\beta_{03} & -\beta_{03} & 1
\end{array}\right), \mathrm{B}_{1}=\left(\begin{array}{lll}
\phi_{11} & \beta_{11} & \beta_{11} \\
\beta_{12} & \phi_{22} & \beta_{12} \\
\beta_{13} & \beta_{13} & \phi_{33}
\end{array}\right), W=\left(\begin{array}{ccc}
1 & w_{12} & w_{13} \\
w_{21} & 1 & w_{23} \\
w_{31} & w_{32} & 1
\end{array}\right),
$$

and $*$ indicates the Hadamard product giving the element-wise product of two matrices.

The general $\operatorname{VAR}(p)$ form of (12) is:

$$
\left(B_{0} * W_{t}\right) y_{t}=\lambda+\left(B_{1} * W_{t-1}\right) y_{t-1}+\ldots+\left(B_{p} * W_{t-p}\right) y_{t-p}+\varepsilon_{t}
$$

where $y_{t}, \varepsilon_{t}$, and $\lambda$ are $(n \times 1)$ vectors, $B_{j},(j=0,1, \ldots, p)$ and $W$ are $(n \times n)$ matrices, and $\left(B_{j} * W_{t-j}\right)$ are the effective parameter matrices.

Equation (13) constitutes the structural VAR model that forms the basis of the estimates in the remainder of the paper. This model differs from the Sims-Bernanke type of structural VAR in four ways. ${ }^{7}$ First, since $W$ is known the model in (13) is over-identified, whereas SimsBernanke models are exactly identified. Second, the model in (13) is extremely parsimonious, whereas Sims-Bernanke models are highly over-parameterised. Third, in (13) $\operatorname{Var}\left(\varepsilon_{t}\right)=\Omega$ may 
not necessarily be diagonal (and it is possible to test for its diagonality), whereas Sims-Bernanke models assume the diagonality of $\Omega$ a priori. Fourth and finally, $W_{t}$ is allowed to change over time in (13), which introduces a changing parameter structure into the model. This structure is critical to stabilize estimates during major shocks such as the Asian crisis and to generate preand post-crisis impulse responses.

Each of these four characteristics differentiating the model in (13) from the standard Sims-Bernanke framework are important additions to the literature on structural VARs. The methodology developed in this section may be useful in a wide variety of other applications with a shortage of realistic, theory-based identification restrictions.

\section{DATA}

Although the model derived in Section 2 only includes two sets of variables (output growth for each country and export shares linking each pair of countries), compiling consistent time series for a sample of countries including the major Asian economies was not trivial. This section summarizes the key characteristics of this data set, and the appendix describes sources and the compilation process in detail.

We focus on 11 countries and 1 group: Indonesia, Malaysia, the Philippines, Thailand, Hong Kong, Singapore, South Korea, Taiwan, China, Japan, the U.S. and the rest of the OECD. The first 4 countries are also referred to as the ASEAN- 4 and the second 4 countries as the NIE4. The rest of the OECD is abbreviated as ROECD and includes all members of the OECD except Japan, South Korea, and the U.S. Statistics for the ROECD are calculated as the weighted-average effect of all countries in the group, so that the ROECD can be interpreted as

\footnotetext{
${ }^{7}$ For more information on the canonical structural VAR, see Blanchard and Watson (1986), Bernanke (1986) or Sims (1986).
} 
one large "country". ${ }^{8}$ Our estimates focus on the period from the first quarter of 1978 through the second quarter of $1998 .^{9}$

We use quarterly data on real GDP to measure output and the logarithm of first differences to calculate growth rates. We utilize data on merchandise exports between countries to measure bilateral-trade flows. ${ }^{10}$ Next, we calculate the export-share matrix $(W)$ as a 12 -quarter moving average of export shares. This strategy has two benefits. First, it allows for the exportshare matrix to vary smoothly over time. Although a constant $W$ matrix would facilitate estimation and forecasting, this is not realistic since trade patterns change significantly over the long time period under consideration. Second, by using 12-quarter moving averages (and assuming that parameter estimates are fairly stable over time), it is still possible to use this model to forecast future changes in output for up to 8 quarters.

The final data set consists of 12 series of real GDP growth rates and 132 series of export shares, each compiled on a quarterly basis from 1978 through 1998. Figure 1 graphs a selection of the series on export shares and reveals a number of interesting patterns. First, the major export markets for most Asian countries are the U.S. and the ROECD, followed by Japan. The one exception is Indonesia, for which Japan is the largest export market. Second, the share of Hong Kong's exports going to China has grown rapidly, although this statistic may include a large number of re-exports. Third, a larger share of exports from Singapore goes to the ASEAN-4 than from Taiwan. This could partially explain why the Asian crisis had a greater impact on Singapore than on Taiwan. Fourth, exports between the ROECD and the U.S. are so large that exports from

\footnotetext{
${ }^{8}$ Weights are equal to each country's GDP in the current period. More specifically, $y_{R O E C D, t}=\sum_{k} w_{k t} y_{k t}$ where: $k$ is an index for each country in the ROECD; $w_{k t}$ is country $k$ 's PPP-adjusted GDP as a share of total ROECD GDP in period $t$; and $y_{k t}$ is country $k$ 's growth rate in period $t$.

${ }^{9}$ We begin in the first quarter of 1978 because this is the first year with reliable GDP data for China. We utilize export data starting in the first quarter of 1975 to calculate the necessary moving averages.

${ }^{10}$ Ideally, we would also like to include service exports between countries. Unfortunately, this data is not consistently available for our sample of countries and years.
} 
these two countries to other nations are relatively negligible. Finally, China continues to be the smallest export market for all countries in the sample except Hong Kong.

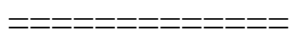

Figure 1

\section{ESTIMATION}

This section uses the data described above to estimate the model in (13). We set $p=4$ in order to account for a stationary seasonal effect. ${ }^{11}$ When $p=4$ there are 708 VAR coefficients in (13), but only 108 coefficients need to be estimated (12 in $\mathrm{B}_{0}$ and 24 in $\mathrm{B}_{\mathrm{j}}$ for $j=1, \ldots, 4$ ). In addition, the variance-covariance matrix ( $\Omega$ ) includes 98 unknowns. We utilize four lags of each $y_{i t}$ $(i=1,2, . ., 12)$ as instruments. In other words, we use lagged values of the growth rates for all the countries (and regions) in the sample as instruments. It is worth emphasizing that this approach is only possible due to the assumption in the structural model that the growth rates in all countries except $i$ are included as a single trade-weighted aggregate variable and not as separate explanatory variables. ${ }^{12}$

We use ordinary-least squares (OLS), two-stage least squares (2SLS), and three-stage least squares (3SLS) to estimate the model and find similar results under each estimation procedure. ${ }^{13}$ The 2 SLS standard errors were roughly the same as (or slightly larger than) the OLS standard errors. The 3SLS standard errors were 1 to 15 percent smaller than the 2SLS standard

\footnotetext{
${ }^{11}$ Despite the fact that the data is seasonally adjusted, tests of the residuals suggest that all of the seasonal variation has not been removed. Allowing $p=4$ removes this seasonal effect.

${ }^{12}$ Regressing each $y_{t}^{f}$ on the above set of instruments yields $\mathrm{R}^{2}$ s around 0.8 for all countries (and regions) except for the U.S. for which the $\mathrm{R}^{2}$ is 0.65 . These $\mathrm{R}^{2}$ s are reasonably large for growth rate regressions, suggesting that the instruments are of acceptable quality.

${ }^{13} \mathrm{We}$ are unable to implement a FIML procedure due to the interaction between $\mathrm{y}_{\mathrm{t}}$ and $\mathrm{W}_{\mathrm{t}}$. We estimate the model with and without an intercept. Our discussion focuses on results without the intercept because when we include a non-zero intercept, the intercept is never significant and coefficient standard errors increase with virtually no change in the error variances.
} 
errors and slightly larger than the OLS standard errors for 13 estimates. Although these asymptotic standard errors suggest that 3SLS may be the optimal estimation technique, we adopt 2SLS in our base analysis for two reasons. First, the root mean-squared errors (RMSEs) of the 2SLS-based forecasts were smaller than those of the 3SLS-based forecasts. Second, the impulse responses based on the 3SLS estimates were substantially larger than those based on the 2SLS estimates. As discussed below, the difference appears to result from the accumulation of estimation errors under the 3SLS.

A closer examination of the 2SLS residual-correlation matrix (reported in Table 1) indicates why these estimates are better than 3SLS for forecasting and estimating impulse responses. To test for non-zero correlations, we compute the Breusch-Pagan Lagrange-multiplier test statistic $\lambda=T \sum r_{i j}^{2}$ recursively by arranging the correlations $\left(r_{i j}\right)$ in ascending order and comparing them to the Chi-square critical values. ${ }^{14}$ Although the test rejects the diagonality of $\Omega$, the recursive test indicates that only five correlations (bold in Table 1) are significantly different from zero. As a result, the unrestricted $\hat{\Omega}$ causes the inferior performance of the 3 SLS estimates.

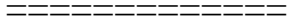

Table 1

The negative and statistically significant correlations in Table 1 are counter-intuitive. One possibility is that they are statistical artifacts arising from poor data quality. As discussed in Section 3, data compilation was a difficult task. The other possibility is that the negative correlations may be capturing the effect of one or more omitted variables, such as cross-country linkages other than direct trade flows. These omitted variables are extremely difficult (if not

\footnotetext{
${ }^{14}$ The degrees of freedom for the Chi-square distribution equals the number of correlations used in $\lambda$. See Judge et al. (1988), p. 456.
} 
impossible) to measure, especially at the high frequency that forms the basis of these estimates. For example, the large negative correlation between the U.S. and ROECD (-0.45) could be explained by the fact that exports from these two regions compete in third markets (such as Asia). An unexpected appreciation of the dollar would improve the competitiveness (and therefore volumes) of exports from the ROECD and reduce the competitiveness (and therefore volumes) of exports from the U.S., therefore driving the negative correlation between the two countries. There are a wide variety of potential omitted variables, such as competition in third markets, which may not be fully captured in the estimates in Table 1.

As a final extension to the analysis in Table 1, we examine the recursive estimates of the coefficients on the $\alpha_{i}$ in (8) to see whether they converge to constant values. These coefficients are calculated by arranging the $i$ th equation of (13) in the format of (10) and then setting $\alpha_{i}=\sum_{j=0}^{4} \beta_{j i} /\left(1-\sum_{j=1}^{4} \phi_{j i}\right)$. The 2SLS recursive parameter estimates are reported in Table 2 and show that the $\alpha_{i}$ 's remain reasonably constant as the estimation period is extended. ${ }^{15}$ This stability is particularly noteworthy during the Asian crisis and results from the changing trade patterns captured by the $W_{t}$ matrix.

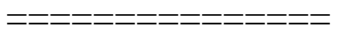

Table 2

\section{FORECASTING PERFORMANCE}

This section examines the (out-of-sample) forecasting performance of the model estimated in Section 4. It evaluates the impact of using a constant export-share weighting matrix $(W)$ and

\footnotetext{
${ }^{15}$ The main exception is the Philippines, which appears to have a discernible trend. The fitted equation for the Philippines had the poorest fit due to the presence of a strong seasonal effect that cannot be fully removed by an adjustment such as the X11.
} 
gauges the magnitude of the forecasting error as the forecasting horizon increases. For a given $W$ matrix and $p=4$, the forecasting model based on (13) can be written as:

$$
y_{t}=A_{1} y_{t-1}+A_{2} y_{t-2}+A_{3} y_{t-3}+A_{4} y_{t-4}+u_{t}
$$

where $A_{i}=\left(B_{0} * W\right)^{-1}\left(B_{i} * W\right), i=1, . .4$ and $u_{t}=\left(B_{0} * W\right)^{-1} \varepsilon_{t}$.

For a given $W$ at time $t$ we generate 1-step to 4-step-ahead forecasts from the first quarter of 1994 through the second quarter of 1997 by increasing the time distance between $W_{t}$ and the forecast point. For example, we use $W$ in the first quarter of 1994 to generate 1-step-ahead forecasts through the second quarter of 1997. Then we arrange the associated forecast errors for each country in a matrix such that the principle diagonal represents a zero distance between $W_{t}$ and the forecast point, the next upper diagonal corresponds to a distance of one quarter, etc. The diagonal entries below the principle diagonal can be ignored because they correspond to using future export shares to forecast present values. With four-step forecasts, this exercise provides 48 forecast error matrices $(4 \text { steps } \times 12 \text { countries })^{16}$.

Next we tabulate the mean errors and RMSEs of the forecasted GDP growth rates corresponding to nine $W$ matrices, $\left(W_{t-i}, i=0,1, \ldots, 8\right)$. Mean errors and RMSEs are not significantly affected by the choice of these $W$ matrices. Due to the time lag before export data is available, the most relevant $W$ matrix for forecasting is $W_{t-2}$ (export data two quarters before the forecast point). Table 3 reports the RMSEs of forecasts corresponding to $W_{t-2}$. "Base model" refers to the central estimates used in this paper (based on the model developed in (13)). "Standard VAR" reports RSMEs of forecasts based on the standard VAR model that is frequently used in other papers. Both models use the same variables and set $p=4$. In other words, this forecasting exercise compares the non-linear model of export shares and output growth that

16 We only use forecasts up to four steps in order to focus on annual GDP growth rates. Growth rates beyond four quarters provide minimal additional information because forecasted growth rates (beyond 4steps) are computed against a forecasted base. 
is the focus of this paper with a simple, linear unrestricted VAR model of output growth that has been used in other work.

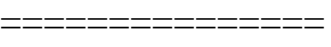

Table 3

Table 3 shows that, as expected, forecast errors increase at longer forecast horizons. For most countries, however, the estimates have fairly low errors and provide respectable forecasts. The results for the base model developed in this paper are especially impressive when compared to the RSMEs for the standard VAR that has traditionally been used in this literature for impulseresponse analysis.

\section{IMPULSE-RESPONSE ANALYSIS}

This section uses the model estimated above to calculate a series of impulse-response functions. It shows how a shock to each country in the sample is predicted to directly and indirectly impact other countries through bilateral-trade linkages and output-multiplier effects. In order to calculate these impulse responses, we write the moving-average representation of (14) as:

$$
y_{t}=\sum_{i=0}^{\infty} C_{i} u_{t-i}=\sum_{i=0}^{\infty} C_{i}\left(B_{0} * W\right)^{-1} \varepsilon_{t-i}
$$

where the $C_{i}$ matrices are computed from the recursive relationship:

$$
\begin{aligned}
& C_{0}=I_{12} \\
& C_{i}=\sum_{j=1}^{i} C_{i-j} A_{j}, i=1,2, \ldots
\end{aligned}
$$

and if $\Omega$ is diagonal the impulse response matrix is $C_{i}\left(B_{0} * W\right)^{-1}$. Thus the effect of a unit shock in the $j$ th country on itself and others at time $t+i$ is given by $\partial y_{t+i} / \partial \varepsilon_{j t}=C_{i} b_{j}$, where $b_{j}$ is the $j$ th column of $\left(B_{0} * W\right)^{-1}$. Instead of a unit shock we may use a one-standard deviation 
shock to account for the relative variability of different shocks. For diagonal $\Omega$, using the result that $P \Omega P^{\prime}=I$, where $P=\operatorname{diag}\left(\sigma_{1}^{-1}, \sigma_{2}^{-1}, \ldots ., \sigma_{n}^{-1}\right)$, we can insert $P^{-1} P$ in front of $\varepsilon_{t-i}$ in

(15) to obtain the standardized innovations $v_{t}=P \varepsilon_{t}$ with $\operatorname{Var}\left(v_{t}\right)=I$. The corresponding impulse response matrix is $C_{i}\left(B_{0} * W\right)^{-1} P^{-1}$ from which we obtain $\partial y_{t+i} / \partial \varepsilon_{j t}=C_{i} b_{j} \sigma_{j}$, where $\sigma_{j}$ is the innovation standard deviation of country $j$. Thus the impulse responses corresponding to a unit shock can be re-scaled to obtain the effect of a shock of a desired magnitude. ${ }^{17}$

Next, we generate impulse responses for 20 quarters using two different $W$ matrices: from the fourth quarter of 1996 (before the Asian crisis) and from the second quarter of 1998 (during the Asian crisis). Since the export-share matrices are calculated as 12-quarter moving averages, the two sets of impulse responses are very similar. To avoid repetition, we focus on results obtained using the latter weighting matrix.

Figure 2 graphs the marginal impulse responses for U.S. GDP growth from a unit random shock to each country/region in the sample. Not surprisingly, shocks to the U.S. and ROECD are predicted to have the largest effect on the U.S. economy. The impact of a shock to the NIE4 is predicted to be larger than a one-unit shock to Japan. In each case, most of the impact of the shock affects the U.S. within the first year, and after about 4 quarters, the impulse responses are very small and close to zero.

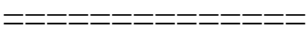

Figure 3

\footnotetext{
${ }^{17}$ See Hamilton, 1994, Ch. 11. Ideally the structural model should be specified in such a way that $\Omega$ becomes diagonal. Since $\Omega$ does not appear to be diagonal (Table 1) we resorted to using the generalized impulse-response method advocated by Pesaran and Shin (1998). This procedure, however, generated a large number of negative values. Therefore, we use $C_{i}\left(B_{0} * W\right)^{-1}$ to compute impulse responses.
} 
More informative than graphs of impulse responses are estimates of the multiplier effects linking output growth across countries. Table 4 reports the cumulative impact of a one-unit, positive shock in each country on the GDP growth of every country in the sample after four quarters $^{18}$. The column headings list the countries where the shocks originate, and the row headings indicate the impacted countries. The last row of the table provides the standard deviations of the regression residuals. These numbers can be used to gauge the relative volatilities of structural shocks in different countries; multiplying each column by its standard deviation provides the estimated effects of a one standard-deviation shock.

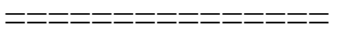

Table 4

Table 4 shows a number of patterns. First, in most cases a shock to each country has a larger impact on growth within that country than on any other countries. Second, shocks to the largest economies (Japan, the ROECD, and the U.S.) generally have larger predicted multiplier effects than shocks to smaller countries. Third, one-unit shocks to China are often predicted to have a larger impact than shocks to other Asian countries (with the exception of Japan) - despite China being viewed as a fairly closed economy with relatively weak trade linkages with other countries in the sample (as shown in Figure 1).

Fourth, shocks to the relatively small economies of Indonesia, Malaysia, the Philippines and Thailand are predicted to have a substantial impact on other Asian economies, such as Singapore and South Korea. This suggests that the spread of the Asian crisis from the ASEAN4 to the NIEs should not have been surprising. Finally, despite the relative proximity of Japan to Asia, shocks to the ROECD and U.S. are predicted to have larger multiplier effects on most Asian countries than shocks to Japan. For example, the average multiplier effect of a shock to the

${ }^{18}$ Impulse responses show the presence of some seasonal effects. Cumulative responses at annual intervals 
U.S. or ROECD on the Asian economies (excluding Japan) is almost 2 times the average impact of a shock to Japan. ${ }^{19}$ According to these estimates, Asia is much more affected by a slowdown in the U.S. economy than a comparable slowdown in Japan.

The statistics in Table 4 capture not only how a shock to one country directly impacts other countries, but also the initial shock to one country spreads through a chain of output effects in other countries. These indirect multiplier effects tend to be much larger and follow very different patterns than would be predicted by focusing only on bilateral-trade flows between countries. Table 5 makes this point by focusing on how individual countries are affected by shocks that originate in other countries in the sample. In the "rank by exports" columns, the table lists the main trading partners (ranked by export shares) of the country listed in the heading of that section of the table. In the "ranked by multiplier" columns, the table lists the multiplier effects on the country in the heading from a shock originating in each of the countries listed in the rows. These multiplier effects are taken from Table 4 and then normalized by setting "owncountry" multipliers to unity. This removes the scaling effect that results from using one-unit shocks versus one standard-deviation shocks.

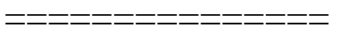

Table 5

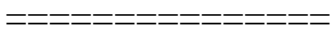

Table 5 clearly shows that the predicted impact of a shock working directly through export flows can be very different than the predicted impact of a shock working through multiplier effects on output growth and trade linkages between the entire sample of countries. The table also shows a number of noteworthy patterns. First, and not surprisingly, shocks to the

remove this effect.

${ }^{19}$ The average effect is calculated as the unweighted average of the individual effects on each Asian country in the sample. 
largest economies have the largest multiplier effects on other countries. For most countries in the sample, the ROECD, U.S. and/or Japan are at the top of the "ranked by multiplier" column.

Second, shocks to a country's most important bilateral-trade partners can be relatively less important than shocks to other countries when the full multiplier effects are taken into consideration. For example, Hong Kong is China's largest trading partner (and vice versa) and Singapore is Malaysia's largest trading partner (and vice versa). According to the multiplier effects, however, a one-unit shock to any of these countries would have less of an impact on their main trading partner than a one unit shock to the ROECD or U.S. Third, direct trade flows from Taiwan to China are small (with China at the bottom of Taiwan's list of export markets), but the multiplier effect of a shock to China on Taiwan's GDP growth is predicted to be much larger. This captures the fact that a large share of Taiwan's exports go to Hong Kong and are then reexported to China.

A final noteworthy point is the predicted impact of the Asian crisis on output growth in Singapore and Taiwan. Singapore was much more affected by the crisis than Taiwan. According to Table 5, the combined direct-trade effect from the main "crisis countries" (the sum of the export effects from Indonesia, Malaysia, the Philippines, South Korea, and Thailand) was 0.31 for Singapore and 0.11 for Taiwan. According to the output-multiplier effect, however, the combined impact of the same crisis countries on Singapore was 1.0, whereas for Taiwan it was only 0.63 . In other words, the output-multiplier effect predicts that the impact of the Asian crisis on Singapore relative to on Taiwan would be twice as large than if the crisis was just transmitted via the direct direct-trade effect.

\section{CONCLUSION}

This paper develops a structural VAR model to estimate how a shock to one country affects output in other countries. It focuses on two types of cross-country linkages: direct effects through 
bilateral trade and indirect effects through output multipliers. Estimates suggest that outputmultiplier effects are large and capture an important transmission mechanism that is overlooked in models using only a bilateral-trade matrix. A series of impulse-response functions shows that due to these indirect multiplier effects, a shock to one country can have a large impact on other countries that are relatively minor trading partners. These estimates provide insight on the propagation and scope of the Asian crisis.

In order to estimate these direct trade linkages and output-multiplier effects, the paper develops a VAR model that uses trade flows to link output growth across countries. This structural model is a significant improvement over the VARs previously used in this literature. It uses economic theory to construct a new series of identification assumptions that avoid overparameterisation and the need for arbitrary triangularization. A key contribution of this model is that cross-country relationships are allowed to vary over time - a critical feature when estimating relationships over long periods or after a crisis. Model estimates suggest that this methodology not only provides relatively good forecasts, but also performs significantly better than the standard VARs.

The framework and estimates of this paper could be extended in a number of directions. For example, the sample of countries could be expanded and numerous variables could be added to the model - from country-specific macroeconomic measures to cross-country financial flows. Taken as a whole, however, the paper makes two important contributions. First, the framework and modelling approach may be useful in a wide variety of other applications with a shortage of realistic, theory-based identification restrictions. Second, the estimates suggest that indirect cross-country linkages through output-multiplier effects are important determinants of how shocks and crises are transmitted internationally. 


\section{DATA APPENDIX}

The database consists of 12 GDP series and 132 export-share series (11 series for each of the 12 countries/regions). Each series includes quarterly data from the first quarter of 1975 through the second quarter of 1998 .

The GDP statistics were taken from a number of sources. The main source is the International Financial Statistics CD-ROM and CEIC (Hong Kong based) which report constantprice, quarterly GDP statistics (expressed in local currencies). ${ }^{20}$ Some series were available in seasonally adjusted form. Unadjusted series were seasonally adjusted using the X-11 procedure. On several occasions, quarterly GDP statistics for Malaysia, Indonesia, the Philippines, China and Thailand had to be interpolated. This interpolation was done using the Chow-Lin relatedseries technique. ${ }^{21}$ The GDP data for the ROECD (all members of the OECD except Japan, South Korea and the U.S.) was obtained from the International Statistical Yearbook (ISY) CD-ROM and reported in constant U.S. dollars. The growth rates of this series closely match the growth rates of the OECD GDP index available in the OECD Economic Indicators. ${ }^{22}$

Export data was obtained from the Direction of Trade Statistics (various issues), Taiwan Economic Data Centre, and Taiwan Statistical Yearbook. Export data is reported as freight-onboard (f.o.b) in U.S. dollars. A number of adjustments had to be made to this data.

First, Singapore's exports to Indonesia are not publicly available, although Indonesia publishes data on imports from Singapore. Singapore's export data rarely matches the import

\footnotetext{
${ }^{20}$ The Japan GDP series on the IFS CDROM has a mistake for 1979 which we corrected using the CEIC database.

${ }^{21}$ A detailed analysis in Abeysinghe and Lee (1998) and Abeysinghe and Gulasekaran (2000) suggests that these interpolated series are of good quality. These data series can be downloaded from http://courses.nus.edu.sg/course/ecstabey/Tilak.html.

${ }^{22}$ The one exception is for 1980 when the ISY series reports a growth rate of 4.6 percent whereas the Economic Indicators reports a growth rate of 1.2 percent. Since the former number appears to be a mistake, we replaced the ISY quarterly growth rates for 1980 with statistics from the Economic Indicators and worked out an index for the ROECD based on ROECD growth $=\left(\right.$ OECD growth- $\mathrm{w}_{1}$.US growth- $\mathrm{w}_{2}$.Japan growth $) /\left(1-\mathrm{w}_{1}-\mathrm{w}_{2}\right)$, where $\mathrm{w}_{1}=0.3635$ and $\mathrm{w}_{2}=0.1491$ are the 1990 PPP-based weights used for the U.S. and Japan, respectively, in OECD GDP calculations.
} 
data from other countries, however, because Singapore includes re-exports in its exports whereas its trading partners often classify these re-exports as imports from the originating country. Yamamoto and Noda (1997) show that as the re-export content of Singapore's exports increases, the "consistency ratio" (imports from Singapore recorded in the other country divided by Singapore's exports) falls. Since Malaysia has a similar pattern of trade and re-exports with Singapore as Indonesia, we use Malaysia's consistency ratio (0.61) to adjust the Indonesian import series and derive the corresponding export share.

The second adjustment to the export data is for China. There are a number of gaps in China's export data. Therefore, we use imports from China reported by China's trading partners as estimates of China's exports. It is also difficult to obtain trade data between China and Taiwan. The best data source that we were able to find is from the Taiwan Economic Data Center. This data shows that direct trade between the two countries was very small in the early 1990s. Most of the trade between Taiwan and China takes place through Hong Kong, in which case the destination country is recorded as Hong Kong. 


\section{REFERENCES}

Abeysinghe, Tilak (2001a). "Thai Meltdown and Transmission of Recession within the ASEAN4 and NIE4." In Stijn Claessens and Kristin Forbes, eds. International Financial Contagion. Boston, MA: Kluwer Academic Publishers, pp. 225-240.

Abeysinghe, Tilak (2001b). "Estimation of Direct and Indirect Impact of Oil Price on Growth." Economics Letter, 73: 147-153.

Abeysinghe, Tilak and C. Lee (1998). "Best Linear Unbiased Disaggregation of Annual GDP to Quarterly Figures: The Case of Malaysia." Journal of Forecasting 17: 527-37.

Abeysinghe, Tilak and Rajaguru Gulasekaran (2000). "Historical Quarterly GDP Estimates for China and ASEAN4." Mimeo.

Ball, R.J. ed. (1973). The International Linkage of National Economic Models. Amsterdam: North-Holland Publishing Co.

Bernanke, Ben (1986). "Alternative Explanations of the Money-Income Correlation." CarnegieRochester Conference Series on Public Policy 25(0, Autumn): 49-100.

Blanchard, Olivier and Mark Watson (1986). "Are business cycles all alike?" In Robert Gorden, ed. The American Business Cycle: Continuity and Change. Chicago: University of Chicago Press, pp. 123-156.

Claessens, Stijn, Rudiger Dornbusch, and Yung Chul Park (2001). "Contagion: Why crises spread and how this can be stopped." In Stijn Claessens and Kristin Forbes, eds. International Financial Contagion. Boston, MA: Kluwer Academic Publishers, pp. 19-41.

Claessens, Stijn and Kristin Forbes, eds. (2001). International Financial Contagion. Boston, MA: Kluwer Academic Publishers.

Forbes, Kristin (2001). "Are Trade Linkages Important Determinants of Country Vulnerability to Crises?" NBER Working Paper No. 8194. 
Forbes, Kristin (2000). "The Asian Flu and Russian Virus: Firm-level Evidence on How Crises are Transmitted Internationally.” NBER Working Paper No. 7807.

Glick, Reuven and Andrew Rose (1999). "Contagion and Trade: Why are Currency Crises Regional?” Journal of International Money and Finance 18: 603-627.

Goldstein, Morris (1998). The Asian Financial Crisis: Causes, Cures, and Systemic Implications. Washington, DC: Institute for International Economics.

Hamilton, J.D. (1994). Time Series Analysis. Princeton University Press.

International Monetary Fund (1999). World Economic Outlook: May 1999. Washington, DC: International Monetary Fund.

Judge, George, R. Carter Hill, William Griffiths, H. Lutkepohl and T.C. Lee (1988). Introduction to the Theory and Practice of Econometrics, $2^{\text {nd }}$ ed. New York: John Wiley \& Sons.

McKibbin, Warwick and Jeffrey Sachs (1991). Global Linkages: Macroeconomic Interdependence and Cooperation in the World Economy. Washington, D.C.: The Brookings Institution.

Pesaran, Hashem and Yongcheol Shin (1998). "Generalized Impulse Response Analysis in Linear Multivariate Models." Economics Letters 58(1, January): 17-29.

Sims, Christopher (1986). "Are Forecasting Models Usable for Policy Analysis?' Federal Reserve Bank of Minneapolis Quarterly Review 10(1,Winter): 2-16.

Yamamoto, Yoshitsugu and Y. Noda (1997). Consistency of Commodity Trade Statistics in the Asian Pacific Region: Comparison of Export Values and Corresponding Import Values. Institute of Developing Economies Series No. 74.

Zellner, Arnold and F.C. Palm (1974). "Time Series Analysis and Simultaneous Equation Econometric Models." Journal of Econometrics 2: 17-54. 

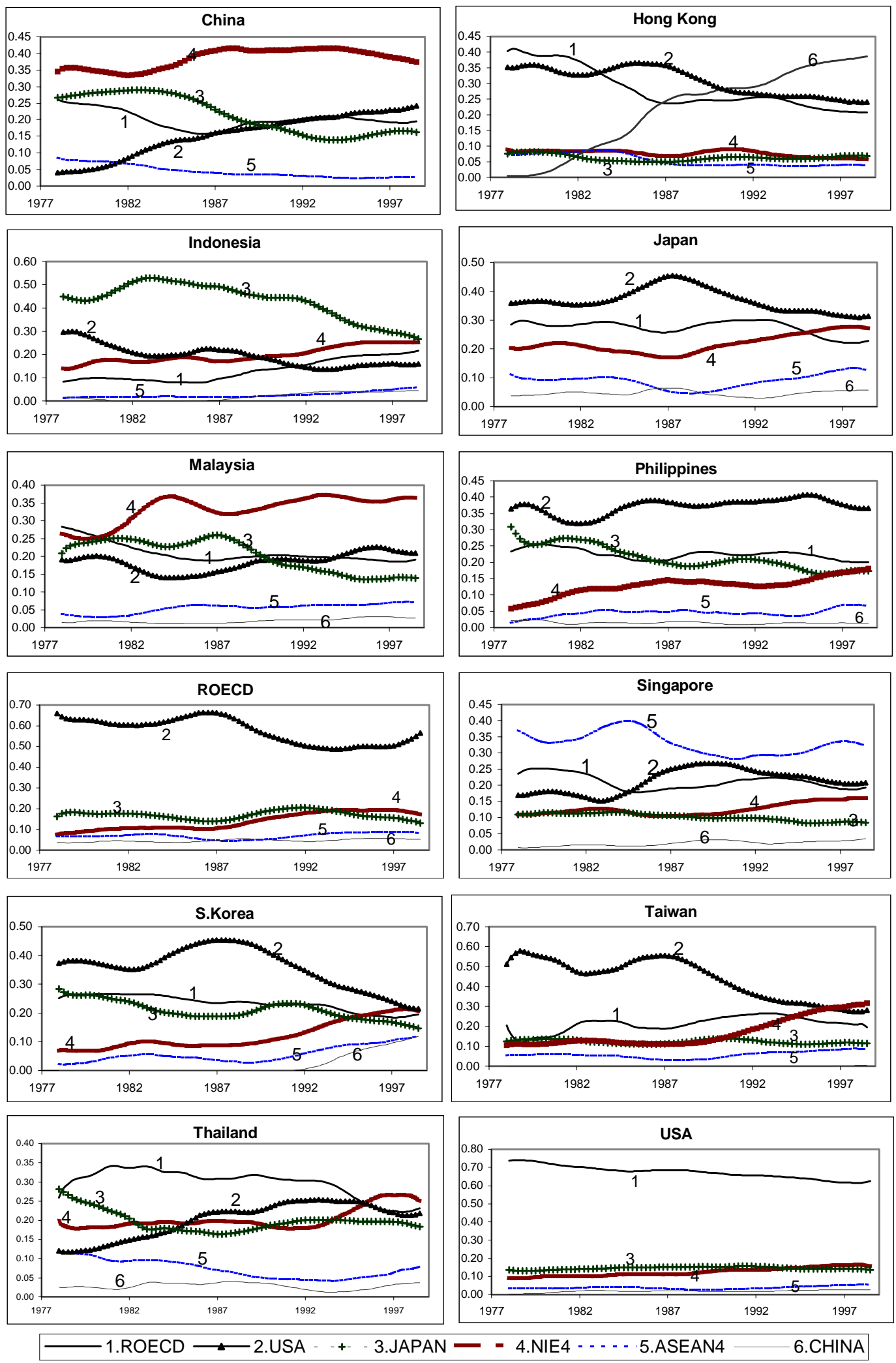

\section{Figure 1}

Export Shares 


\section{Figure 2}

\section{Impulse Responses on U.S. GDP Growth}

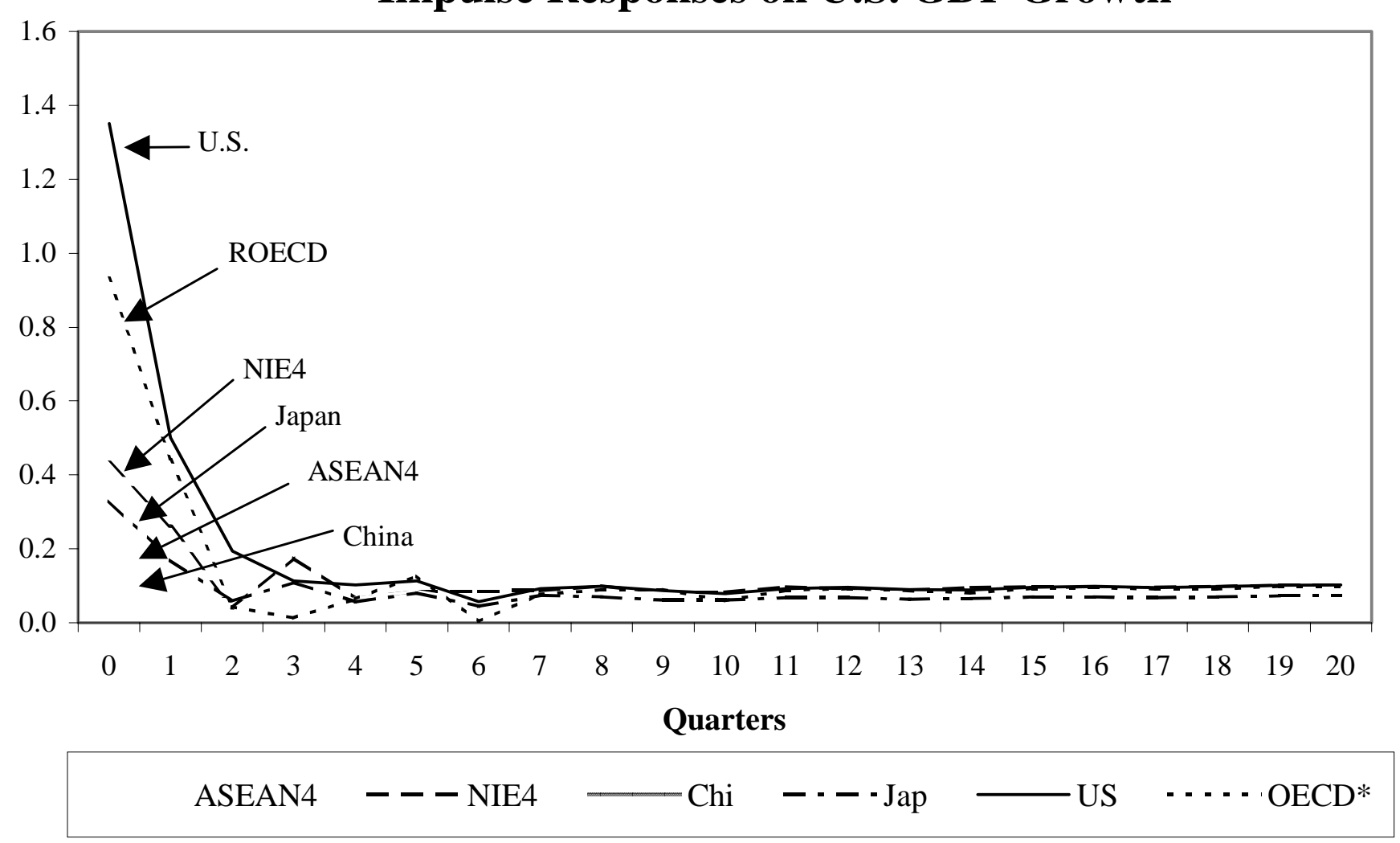

Notes: These are the marginal impulse responses on U.S. GDP growth from a one-unit shock in the originating country. OECD* or ROECD is the rest of the OECD, i.e. the OECD excluding the U.S., Japan, and South Korea. 
Table 1

Residual Correlations from 2SLS Regressions

\begin{tabular}{|c|c|c|c|c|c|c|c|c|c|c|c|c|}
\hline & China & Hong Kong & Indonesia & Japan & Malaysia & Philippines & ROECD & Singapore & S. Korea & Taiwan & Thailand & U.S. \\
\hline China & 1.00 & & & & & & & & & & & \\
\hline Hong Kong & 0.08 & 1.00 & & & & & & & & & & \\
\hline Indonesia & -0.19 & -0.11 & 1.00 & & & & & & & & & \\
\hline Japan & 0.06 & -0.19 & -0.14 & 1.00 & & & & & & & & \\
\hline Malaysia & -0.36 & -0.27 & 0.34 & -0.05 & 1.00 & & & & & & & \\
\hline Philippines & -0.06 & 0.18 & 0.08 & 0.05 & 0.01 & 1.00 & & & & & & \\
\hline ROECD & -0.04 & -0.16 & 0.03 & 0.09 & -0.03 & -0.25 & 1.00 & & & & & \\
\hline Singapore & 0.12 & 0.26 & -0.08 & -0.21 & -0.06 & -0.05 & -0.18 & 1.00 & & & & \\
\hline S. Korea & 0.03 & 0.16 & -0.22 & -0.03 & -0.05 & 0.00 & 0.03 & -0.12 & 1.00 & & & \\
\hline Taiwan & -0.04 & 0.19 & 0.12 & -0.24 & -0.05 & 0.15 & -0.18 & 0.15 & -0.05 & 1.00 & & \\
\hline Thailand & -0.16 & 0.08 & -0.09 & -0.33 & -0.07 & 0.05 & -0.06 & 0.18 & 0.08 & 0.24 & 1.00 & \\
\hline U.S. & -0.08 & -0.14 & 0.09 & -0.19 & -0.01 & 0.09 & -0.45 & 0.05 & -0.42 & 0.12 & 0.01 & 1.00 \\
\hline
\end{tabular}

Note: Bold indicates significance at the 5 percent level. 
Table 2

Recursive Estimates of Alpha Coefficients ${ }^{1}$

\begin{tabular}{lcccccc}
\hline Country & $\mathbf{1 9 7 8 - 9 2}$ & $\mathbf{1 9 7 8 - 9 3}$ & $\mathbf{1 9 7 8 - 9 4}$ & $\mathbf{1 9 7 8 - 9 5}$ & $\mathbf{1 9 7 8 - 9 6}$ & $\mathbf{1 9 7 8 - 9 8 q 2}$ \\
\hline China & 1.99 & 1.99 & 2.05 & 1.99 & 1.95 & 1.80 \\
Hong Kong & 1.49 & 1.43 & 1.35 & 1.27 & 1.26 & 1.21 \\
Indonesia & 1.41 & 1.44 & 1.45 & 1.49 & 1.52 & 1.46 \\
Japan & 0.89 & 0.84 & 0.79 & 0.79 & 0.79 & 0.81 \\
Malaysia & 1.45 & 1.48 & 1.52 & 1.52 & 1.55 & 1.55 \\
Philippines & 0.33 & 0.37 & 0.48 & 0.49 & 0.57 & 0.62 \\
ROECD & 0.64 & 0.62 & 0.65 & 0.62 & 0.62 & 0.64 \\
Singapore & 1.73 & 1.80 & 1.69 & 1.75 & 1.67 & 1.70 \\
S. Korea & 2.27 & 2.25 & 2.22 & 2.22 & 2.17 & 2.07 \\
Taiwan & 2.04 & 2.03 & 2.03 & 1.94 & 1.93 & 1.98 \\
Thailand & 1.92 & 1.93 & 1.98 & 1.97 & 1.68 & 1.70 \\
U.S. & 0.62 & 0.63 & 0.63 & 0.64 & 0.65 & 0.66 \\
\hline
\end{tabular}

Note: (1) Based on 2SLS estimates. 
Table 3

Forecast RMSEs from Base Model and Standard VAR ${ }^{1}$

\begin{tabular}{llcccc}
\hline & & 1-step & 2-steps & 3-steps & 4-steps \\
\hline China & Base Model & 0.73 & 1.13 & 1.35 & 1.50 \\
& Standard VAR & 2.55 & 5.37 & 5.48 & 7.01 \\
Hong Kong & Base Model & 0.92 & 1.53 & 2.24 & 3.31 \\
& Standard VAR & 3.47 & 8.07 & 8.49 & 10.19 \\
Indonesia & Base Model & 1.07 & 1.46 & 1.38 & 1.13 \\
& Standard VAR & 2.12 & 3.05 & 3.18 & 3.42 \\
Japan & Base Model & 0.83 & 1.21 & 1.36 & 1.46 \\
& Standard VAR & 1.56 & 1.96 & 2.09 & 3.36 \\
Malaysia & Base Model & 0.73 & 0.93 & 0.88 & 0.91 \\
& Standard VAR & 1.61 & 4.31 & 4.67 & 5.51 \\
Philippines & Base Model & 0.81 & 1.42 & 2.03 & 2.54 \\
& Standard VAR & 4.71 & 7.24 & 6.91 & 5.74 \\
ROECD & Base Model & 0.43 & 0.61 & 0.91 & 1.18 \\
& Standard VAR & 0.92 & 1.41 & 1.26 & 1.77 \\
Singapore & Base Model & 1.82 & 2.68 & 3.32 & 4.02 \\
& Standard VAR & 2.55 & 4.66 & 6.28 & 9.59 \\
S. Korea & Base Model & 1.42 & 2.05 & 3.02 & 4.16 \\
& Standard VAR & 3.44 & 6.08 & 5.45 & 6.71 \\
Taiwan & Base Model & 0.50 & 0.86 & 1.41 & 2.20 \\
& Standard VAR & 1.99 & 3.97 & 3.92 & 4.82 \\
Thailand & Base Model & 0.58 & 1.18 & 2.01 & 2.92 \\
& Standard VAR & 2.63 & 4.88 & 5.14 & 6.89 \\
& Base Model & 0.47 & 0.71 & 0.66 & 1.08 \\
& Standard VAR & 1.29 & 1.97 & 2.18 & 3.57 \\
\hline
\end{tabular}

Note: (1) "Base Model" is the model developed in this paper and used as the basis for estimation. "Standard VAR" is the model typically used in previous work. The forecast period for both models is 1994Q1-1997Q2 and the weight matrix is $\mathrm{W}_{\mathrm{t}-2}$. Forecasts are GDP growth rates versus the same quarter of the previous year. Parameter estimates for both models are updated recursively. 
Table 4

Output Multipliers:

Cumulative Impulse Responses after Four Quarters

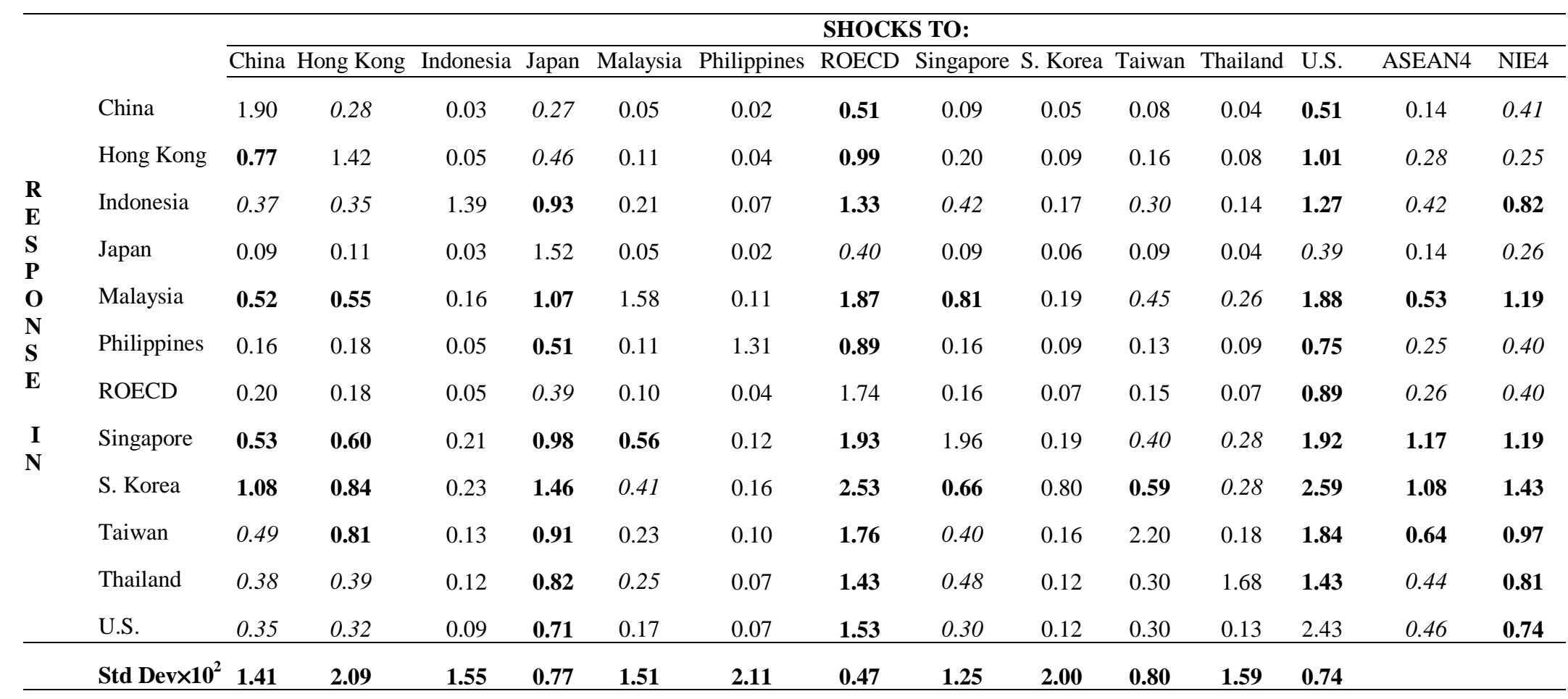

Note: Each row shows the effect on that country's GDP growth from a shock originating in the country listed in the given column. Values greater than 0.50 are written in bold, and values greater than 0.25 (but less than 0.50 ) are written in italics, except own-country effects are not written in bold or italics. ASEAN4 is the sum of the effects of one-unit shocks to Indonesia, Malaysia, the Philippines and Thailand. NIE4 is the sum of the effects of one-unit shocks to Hong Kong, Singapore, South Korea, and Taiwan. When applicable, member countries are excluded from each of these sums. The last row provides standard deviations of the regression residuals (multiplied by 100 to facilitate readability). 
Table 5 - Part 1

Trading Partners Ranked by Export Shares and Multiplier Effects

\begin{tabular}{|c|c|c|c|c|c|c|c|c|c|c|c|}
\hline \multicolumn{4}{|c|}{ CHINA } & \multicolumn{4}{|c|}{ HONG KONG } & \multicolumn{4}{|c|}{ INDONESIA } \\
\hline \multicolumn{2}{|c|}{$\begin{array}{l}\text { Rank by } \\
\text { Exports }\end{array}$} & \multicolumn{2}{|c|}{$\begin{array}{l}\text { Rank by } \\
\text { Multiplier }\end{array}$} & \multicolumn{2}{|c|}{$\begin{array}{l}\text { Rank by } \\
\text { Exports }\end{array}$} & \multicolumn{2}{|c|}{$\begin{array}{c}\text { Rank by } \\
\text { Multiplier }\end{array}$} & \multicolumn{2}{|c|}{$\begin{array}{l}\text { Rank by } \\
\text { Exports }\end{array}$} & \multicolumn{2}{|c|}{$\begin{array}{c}\text { Rank by } \\
\text { Multiplier }\end{array}$} \\
\hline Hong Kong & 0.49 & ROECD & 0.29 & China & 0.34 & ROECD & 0.57 & Japan & 0.28 & ROECD & 0.76 \\
\hline U.S. & 0.36 & U.S. & 0.21 & U.S. & 0.21 & U.S. & 0.42 & ROECD & 0.20 & Japan & 0.61 \\
\hline ROECD & 0.30 & Hong Kong & 0.19 & ROECD & 0.19 & China & 0.41 & U.S. & 0.16 & U.S. & 0.52 \\
\hline Japan & 0.27 & Japan & 0.18 & Japan & 0.07 & Japan & 0.30 & Singapore & 0.09 & Hong Kong & 0.24 \\
\hline Taiwan & 0.09 & S. Korea & 0.07 & Singapore & 0.03 & S. Korea & 0.11 & S. Korea & 0.07 & Singapore & 0.22 \\
\hline S. Korea & 0.06 & Singapore & 0.05 & S. Korea & 0.02 & Singapore & 0.10 & China & 0.04 & S. Korea & 0.21 \\
\hline Singapore & 0.03 & Taiwan & 0.04 & Philippines & 0.01 & Malaysia & 0.07 & Taiwan & 0.04 & China & 0.20 \\
\hline Thailand & 0.01 & Malaysia & 0.03 & Thailand & 0.01 & Taiwan & 0.07 & Hong Kong & 0.03 & Taiwan & 0.14 \\
\hline Malaysia & 0.01 & Indonesia & 0.02 & Taiwan & 0.01 & Thailand & 0.05 & Malaysia & 0.02 & Malaysia & 0.13 \\
\hline Indonesia & 0.01 & Thailand & 0.02 & Malaysia & 0.01 & Indonesia & 0.04 & Thailand & 0.02 & Thailand & 0.08 \\
\hline Philippines & 0.00 & Philippines & 0.01 & Indonesia & 0.01 & Philippines & 0.03 & Philippines & 0.01 & Philippines & 0.05 \\
\hline \multicolumn{4}{|c|}{ JAPAN } & \multicolumn{4}{|c|}{ MALAYSIA } & \multicolumn{4}{|c|}{$\begin{array}{l}\text { PHILIPPINES } \\
\end{array}$} \\
\hline \multicolumn{2}{|c|}{$\begin{array}{l}\text { Rank by } \\
\text { Exports }\end{array}$} & \multicolumn{2}{|c|}{$\begin{array}{c}\text { Rank by } \\
\text { Multiplier } \\
\end{array}$} & \multicolumn{2}{|c|}{$\begin{array}{c}\text { Rank by } \\
\text { Exports } \\
\end{array}$} & \multicolumn{2}{|c|}{$\begin{array}{c}\text { Rank by } \\
\text { Multiplier }\end{array}$} & \multicolumn{2}{|c|}{$\begin{array}{l}\text { Rank by } \\
\text { Exports } \\
\end{array}$} & \multicolumn{2}{|c|}{$\begin{array}{c}\text { Rank by } \\
\text { Multiplier }\end{array}$} \\
\hline U.S. & 0.28 & ROECD & 0.23 & Singapore & 0.21 & ROECD & 1.07 & U.S. & 0.34 & ROECD & 0.51 \\
\hline ROECD & 0.20 & U.S. & 0.16 & U.S. & 0.18 & U.S. & 0.78 & ROECD & 0.18 & Japan & 0.34 \\
\hline S. Korea & 0.07 & Hong Kong & 0.08 & ROECD & 0.17 & Japan & 0.70 & Japan & 0.18 & U.S. & 0.31 \\
\hline Taiwan & 0.07 & S. Korea & 0.07 & Japan & 0.13 & Singapore & 0.41 & Singapore & 0.06 & Hong Kong & 0.13 \\
\hline Hong Kong & 0.06 & China & 0.05 & Hong Kong & 0.06 & Hong Kong & 0.39 & Hong Kong & 0.04 & S. Korea & 0.11 \\
\hline China & 0.05 & Singapore & 0.04 & Taiwan & 0.05 & China & 0.27 & Taiwan & 0.04 & China & 0.09 \\
\hline Singapore & 0.05 & Taiwan & 0.04 & Thailand & 0.04 & S. Korea & 0.23 & Thailand & 0.04 & Singapore & 0.08 \\
\hline Thailand & 0.05 & Malaysia & 0.03 & S. Korea & 0.03 & Taiwan & 0.20 & Malaysia & 0.03 & Malaysia & 0.07 \\
\hline Malaysia & 0.04 & Thailand & 0.03 & China & 0.02 & Thailand & 0.15 & S. Korea & 0.02 & Thailand & 0.06 \\
\hline Indonesia & 0.02 & Indonesia & 0.02 & Indonesia & 0.02 & Indonesia & 0.11 & China & 0.02 & Taiwan & 0.06 \\
\hline Philippines & 0.02 & Philippines & 0.02 & Philippines & 0.01 & Philippines & 0.08 & Indonesia & 0.01 & Indonesia & 0.04 \\
\hline
\end{tabular}

Notes: Multipliers are normalized by setting "own-country" multipliers to unity. The country listed at the top of each part of the table is the country "responding to" a normalized shock originating in each country listed in the lower part of the table. Export shares are based on the 1996 export matrix. 
Table 5 - Part 2

Trading Partners Ranked by Export Shares and Multiplier Effects

\begin{tabular}{|c|c|c|c|c|c|c|c|c|c|c|c|}
\hline \multicolumn{4}{|c|}{ REST OF THE OECD } & \multicolumn{4}{|c|}{ SINGAPORE } & \multicolumn{4}{|c|}{ SOUTH KOREA } \\
\hline \multicolumn{2}{|c|}{$\begin{array}{l}\text { Rank by } \\
\text { Exports }\end{array}$} & \multicolumn{2}{|c|}{$\begin{array}{c}\text { Rank by } \\
\text { Multiplier }\end{array}$} & \multicolumn{2}{|c|}{$\begin{array}{l}\text { Rank by } \\
\text { Exports }\end{array}$} & \multicolumn{2}{|c|}{$\begin{array}{c}\text { Rank by } \\
\text { Multiplier }\end{array}$} & \multicolumn{2}{|c|}{$\begin{array}{l}\text { Rank by } \\
\text { Exports }\end{array}$} & \multicolumn{2}{|c|}{ Rank by Multiplier } \\
\hline U.S. & 0.10 & U.S. & 0.37 & U.S. & 0.18 & ROECD & 1.11 & U.S. & 0.17 & ROECD & 1.46 \\
\hline Japan & 0.03 & Japan & 0.25 & Malaysia & 0.18 & U.S. & 0.79 & ROECD & 0.14 & U.S. & 1.07 \\
\hline Hong Kong & 0.01 & Hong Kong & 0.13 & ROECD & 0.16 & Japan & 0.64 & Japan & 0.12 & Japan & 0.96 \\
\hline S. Korea & 0.01 & China & 0.11 & Hong Kong & 0.09 & Hong Kong & 0.42 & China & 0.09 & Hong Kong & 0.59 \\
\hline China & 0.01 & S. Korea & 0.09 & Japan & 0.08 & Malaysia & 0.36 & Hong Kong & 0.09 & China & 0.57 \\
\hline Singapore & 0.01 & Singapore & 0.08 & Thailand & 0.06 & China & 0.28 & Singapore & 0.05 & Singapore & 0.34 \\
\hline Taiwan & 0.01 & Taiwan & 0.07 & S. Korea & 0.03 & S. Korea & 0.24 & Malaysia & 0.03 & Taiwan & 0.27 \\
\hline Thailand & 0.01 & Malaysia & 0.06 & China & 0.03 & Taiwan & 0.18 & Taiwan & 0.03 & Malaysia & 0.26 \\
\hline Indonesia & 0.01 & Indonesia & 0.04 & Indonesia & 0.02 & Thailand & 0.16 & Indonesia & 0.03 & Indonesia & 0.17 \\
\hline Malaysia & 0.01 & Thailand & 0.04 & Taiwan & 0.02 & Indonesia & 0.15 & Thailand & 0.02 & Thailand & 0.17 \\
\hline Philippines & 0.00 & Philippines & 0.03 & Philippines & 0.02 & Philippines & 0.09 & Philippines & 0.02 & Philippines & 0.12 \\
\hline
\end{tabular}

\begin{tabular}{|c|c|c|c|c|c|c|c|c|c|c|c|}
\hline \multicolumn{4}{|c|}{ TAIWAN } & \multicolumn{4}{|c|}{\begin{tabular}{|l} 
THAILAND \\
\end{tabular}} & \multicolumn{4}{|c|}{ UNITED STATES } \\
\hline \multicolumn{2}{|c|}{$\begin{array}{c}\text { Rank } \\
\text { by Exports }\end{array}$} & \multicolumn{2}{|c|}{$\begin{array}{c}\text { Rank by } \\
\text { Multiplier }\end{array}$} & \multicolumn{2}{|c|}{$\begin{array}{c}\text { Rank } \\
\text { by Exports } \\
\end{array}$} & \multicolumn{2}{|c|}{$\begin{array}{c}\text { Rank by } \\
\text { Multiplier } \\
\end{array}$} & \multicolumn{2}{|c|}{$\begin{array}{c}\text { Rank } \\
\text { by Exports } \\
\end{array}$} & \multicolumn{2}{|c|}{ Rank by Multiplier } \\
\hline U.S. & 0.27 & ROECD & 1.01 & ROECD & 0.20 & ROECD & 0.83 & ROECD & 0.46 & ROECD & 0.88 \\
\hline Hong Kong & 0.23 & U.S. & 0.76 & U.S. & 0.18 & U.S. & 0.59 & Japan & 0.16 & Japan & 0.47 \\
\hline ROECD & 0.21 & Japan & 0.60 & Japan & 0.17 & Japan & 0.54 & S. Korea & 0.04 & Hong Kong & 0.23 \\
\hline Japan & 0.12 & Hong Kong & 0.57 & Singapore & 0.12 & Hong Kong & 0.28 & Taiwan & 0.03 & China & 0.18 \\
\hline Singapore & 0.04 & China & 0.26 & Hong Kong & 0.06 & Singapore & 0.24 & Singapore & 0.03 & Singapore & 0.15 \\
\hline Malaysia & 0.03 & Singapore & 0.21 & Malaysia & 0.04 & China & 0.20 & Hong Kong & 0.02 & S. Korea & 0.15 \\
\hline Thailand & 0.02 & S. Korea & 0.20 & China & 0.03 & Malaysia & 0.16 & China & 0.02 & Taiwan & 0.14 \\
\hline S. Korea & 0.02 & Malaysia & 0.15 & Taiwan & 0.03 & S. Korea & 0.16 & Malaysia & 0.01 & Malaysia & 0.11 \\
\hline Indonesia & 0.02 & Thailand & 0.11 & S. Korea & 0.02 & Taiwan & 0.14 & Thailand & 0.01 & Thailand & 0.07 \\
\hline Philippines & 0.02 & Indonesia & 0.09 & Indonesia & 0.02 & Indonesia & 0.09 & Philippines & 0.01 & Indonesia & 0.06 \\
\hline China & 0.01 & Philippines & 0.08 & Philippines & 0.01 & Philippines & 0.05 & Indonesia & 0.01 & Philippines & 0.05 \\
\hline
\end{tabular}

Notes: Multipliers are normalized by setting "own-country" multipliers to unity. The country listed at the top of each part of the table is the country "responding to" a normalized shock originating in each country listed in the lower part of the table. Export shares are based on the 1996 export matrix. 